\title{
Incidencia del riesgo judicial en el seguro previsional colombiano*
}

\section{Impacts of the Court Rules \\ on the Colombian pension benefit guarantee scheme}

$\{\text { Marco Alejandro Arenas Prada }\}^{* *}$

Recibido: 15 de diciembre de 2019. Aceptado: ro de junio de 2020.

DoI: https://doi.org/I0.1860I/25390406.n4.04

Abogado de la Universidad Externado de Colombia, Magíster en Derecho Privado de la Universidad de los Andes y Especialista en Derecho de Seguros de la Pontificia Universidad Javeriana, Legislación Financiera de la Universidad de los Andes y Seguridad Social de la Universidad Externado de Colombia. Profesor de seguros y riesgos laborales de la Universidad Externado de Colombia y de la Pontificia Universidad Javeriana. Actual Country Manager de Liberty Seguros S.A. Colombia. 


\section{Resumen}

Este documento evalúa el impacto de los fallos judiciales en el Seguro Previsional. Con ese propósito, se analizará el funcionamiento integral de dicho seguro, incluyendo su finalidad, coberturas, requisitos para acceder a los beneficios que del mismo se derivan y los pronunciamientos jurisprudenciales más destacados que han afectado su funcionamiento integral y que, en particular, han generado retos al sector asegurador a la hora de estimar los riesgos asociados al mismo y, por esa vía, establecer las tarifas. El objetivo principal del estudio se centra en evidenciar cómo el riesgo judicial es uno de los componentes más importantes y de más difícil tasación dentro del seguro previsional.

\section{Palabras clave}

Seguro previsional, pensión de invalidez, pensión de sobrevivientes, riesgo judicial, régimen de ahorro individual con solidaridad.

\section{Abstract}

This paper analyzes how court rules impact the Colombian pension benefit guarantee scheme for individual retirement accounts (IRA). First, it studies the scheme's operation, scope, coverage, as well as the requirements to access its benefits, and reviews the most relevant court rules that have affected the full operation of the before-mentioned scheme, creating challenges to the insurance sector when it comes to estimating risks and fees. Thus and thus, this paper points to how the instability created by court rules has become one of the most critical risks of the scheme.

\section{KeYwords}

Pension benefit guarantee scheme, disability pension, survivor pensions, instability of pension schemes, individual retirement accounts. 


\section{INTRODUCCIÓN}

Desde la expedición de la Ley roo de I993, que creó el actual Sistema General de Seguridad Social en Colombia, se adoptó un esquema mixto que le abrió las puertas a administradores privados y no únicamente públicos, como hasta entonces.

El rol del sector asegurador ha sido especialmente importante en el sistema, no solo por su condición de administradores de riesgos laborales, sino también por su rol protagónico a través de la explotación de ramos que se han denominado como seguros de la seguridad social, en los cuales se busca amparar ciertos riesgos asociados a los subsistemas de salud y de pensiones.

Es así como, a través de planes complementarios de salud y en particular de las pólizas de salud o de hospitalización y cirugía, las compañías de seguros otorgan coberturas que buscan llenar las limitaciones propias del plan de beneficios básico y obligatorio. Así mismo, a través de las pólizas de alto costo, se genera un esquema de aseguramiento para los administradores del sistema de salud que permite, de manera efectiva, controlar los gastos asociados al tratamiento de enfermedades de alto costo que puedan aquejar a sus afiliados y que, típicamente, implican un esfuerzo económico mayor para los administradores.

Otro de los seguros de la seguridad social es el obligatorio de accidentes de tránsito, SOAT, que coexiste con los subsistemas de salud y riesgos laborales, y se cataloga como un seguro de primera capa, en la medida que ampara la integridad física de las víctimas de un accidente de tránsito, de forma preferente sobre el sistema de seguridad social, con independencia del origen común o profesional del mismo.

Por su parte, en el subsistema de pensiones coexisten dos regímenes, uno público de prima media con prestación definida, administrado por el Estado colombiano, que además de recibir las cotizaciones de los aportantes, percibe una importante partida del presupuesto nacional, y otro, denominado de ahorro individual con solidaridad, que se compone por las cuentas de cada uno de los afiliados y se nutre de los aportes que estos efectúan, de los rendimientos financieros que los mismos generan y de los bonos pensionales, cuando a ellos haya lugar.

Dentro del subsistema de pensiones, el rol del asegurador ha tenido incidencia en tres ramos en particular: los seguros previsionales, de rentas vitalicias y de conmutación pensional.

En este artículo, me centraré en el papel que juega el seguro previsional en el régimen de ahorro individual con solidaridad y, en particular, abordaré el estudio del impacto de los fallos judiciales en el mismo.

Lo anterior, dado que, para cualquier asegurador, la estimación del riesgo judicial en un seguro de la seguridad social ha cobrado especial interés, por su 
incidencia en los niveles de siniestralidad, pues la posibilidad de que por la vía judicial se flexibilicen los requisitos para acceder a los beneficios, es cada vez más alta.

\section{El seguro previsional}

\subsection{Aspectos generales}

El previsional es un seguro de la seguridad social, obligatorio y con participación de utilidades, que cumple un papel estelar en el Régimen de Ahorro Individual con Solidaridad del Subsistema de Pensiones.

A través del Seguro Previsional se garantiza al cotizante o a sus beneficiarios el reconocimiento de una pensión de invalidez o de sobrevivientes, a través del pago de la suma adicional necesaria para completar el capital requerido para el financiamiento de dichas prestaciones. El monto de la suma adicional corresponderá al valor total requerido para el pago de la pensión de invalidez o de sobrevivientes, menos el saldo acumulado en la cuenta adicional del afiliado y el bono pensional, si lo hubiere. Además, el seguro previsional se ocupa del reconocimiento y pago de los subsidios por incapacidad temporal superiores a los primeros i 80 días, así como al pago de los auxilios funerarios en favor de las personas que acrediten haber sufragado los gastos exequiales del afiliado fallecido.

\subsection{Requisitos PARA ACCEDER a LOS BENEFICIOS}

La suma adicional requerida para financiar una pensión de invalidez o de sobrevivientes es reconocida por la aseguradora previsional siempre que se acredite el cumplimiento de los requisitos legales, esto es, que el afiliado inválido o fallecido, mayor de 20 años de edad, haya cotizado al menos cincuenta semanas dentro de los tres años anteriores al siniestro, entendiendo como tal, la fecha del fallecimiento o de la estructuración de la invalidez.

Además, en el caso de las pensiones de sobrevivientes, los reclamantes deben cumplir con los requisitos exigidos para ser considerados beneficiarios de tal prestación, para lo cual se establecen unos órdenes de prelación en favor del cónyuge o compañero permanente y los hijos. La prestación será vitalicia si se trata de un cónyuge o compañero permanente con más de 30 años de edad o con hijos concebidos con el causante, así como para los hijos inválidos, y será temporal cuando el cónyuge o compañero permanente cuenten con menos de treinta años de edad y no hayan concebido hijos. Así mismo, será temporal para los hijos mientras no alcancen la mayoría de edad (I 8 años) o se encuentren inhabilitados 
para trabajar en razón de estudios, caso en el cual gozarán del beneficio hasta los 25 años, siempre que acrediten que dependían económicamente del padre fallecido y que siguen estudiando.

A falta de cónyuge o compañero permanente y de hijos, recibirán el beneficio los padres, siempre que acrediten depender económicamente de su hijo fallecido. A falta de estos últimos, recibirán la prestación los hermanos inválidos que dependan económicamente del afilado o pensionado fallecido.

En el caso de los menores de 20 años, la legislación exige un número reducido de semanas de cotización (26 semanas), que deben acreditarse en el año anterior a la muerte o a la fecha de estructuración de la invalidez.

Cuando se trata de una pensión de invalidez, el afiliado debe acreditar una pérdida de capacidad laboral igual o superior al $50 \%$, debidamente calificada por el equipo interdisciplinario de la Aseguradora Previsional o por una Junta de Calificación de Invalidez.

\subsection{Monto de LAS PRESTACIONES}

La prestación se liquidará de manera diferenciada, dependiendo del grado de pérdida de capacidad laboral. En esa medida, cuando la PCL oscila entre el $50 \%$ y el $65 \%$, la pensión se liquidará sobre el $45 \%$ del promedio de los salarios sobre los que cotizó en los últimos diez años o fracción y se adicionará un I, 5 \% por cada 50 semanas adicionales a las primeras 500 .

Si la pérdida de capacidad laboral es igual o superior al 66 \%, la pensión corresponderá al $54 \%$ del promedio de los salarios sobre los que cotizó en los últimos diez años o fracción y se adicionará un $2 \%$ por cada 50 semanas adicionales a las primeras 800 .

En el caso de las pensiones de sobrevivientes, si el fallecido es un afiliado, la prestación corresponderá al $45 \%$ del promedio de los salarios sobre los que cotizó el afiliado durante los últimos diez años o fracción y se aplicará un $2 \%$ adicional por cada 50 semanas adicionales a las primeras 500 . Si fallece el pensionado, se reconocerá una sustitución pensional en favor de sus beneficiarios correspondiente al ıoo \% de la mesada pensional que percibía el causante.

Ninguna pensión de sobrevivientes o de invalidez puede ser inferior al equivalente a un salario mínimo mensual legal vigente, ni superior al $75 \%$ del ingreso base de liquidación.

En adición a la referida suma para completar el capital necesario para financiar una pensión de invalidez o de sobrevivientes, el seguro previsional cubre el reconocimiento y pago de subsidios por incapacidad temporal derivados de accidente o enfermedad común, en el periodo que excede de los primeros ciento ochenta ( 180 ) días y, además, se ocupa del reconocimiento de los auxilios 
funerarios en favor de las personas que comprueban haber pagado los gastos de entierro del afiliado o pensionado por invalidez que fallezca.

Para el reconocimiento de los subsidios por incapacidad temporal, será necesario que el equipo interdisciplinario del Asegurador Previsional emita un concepto favorable de recuperación, que se traduce básicamente en que el afiliado aún no tiene unas secuelas consolidadas para proceder con la calificación de pérdida de capacidad laboral y que además, al extender el reconocimiento y pago de los subsidios por incapacidad temporal, se espera que el afiliado sea sometido a un proceso de rehabilitación que redunde en una mejoría en su estado de salud y una consecuente reducción de su pérdida de capacidad laboral. En este punto, es importante mencionar que la finalidad del sistema es la rehabilitación de los afiliados y no el reconocimiento y pago de pensiones de invalidez.

Siguiendo la regla del subsistema de salud y por tratarse de periodos contados a partir del día i 80 de incapacidad temporal, los subsidios se reconocen y pagan sobre el $50 \%$ del ultimo ingreso base de cotización.

En el caso de los auxilios funerarios, existe un beneficiario indeterminado, pero determinable, en la medida que, a diferencia de las pensiones de sobrevivencia, el beneficio no se reconoce en uno orden prestablecido y no es necesario acreditar relación alguna con el causante. Ello, debido a que dicho auxilio se reconoce y se paga en favor de la persona que acredite haber sufragado los gastos de entierro del afiliado.

El auxilio funerario corresponderá al último ingreso base de cotización del fallecido; sin embargo, el beneficio en ningún caso podrá ser inferior a cinco ni superior a diez salarios mínimos legales mensuales vigentes.

\subsection{Contratación del Seguro previsional}

La selección de la aseguradora se realiza mediante un proceso licitatorio abierto y público, convocado por la Administradora de Fondos de Pensiones y al cual deben ser convocadas y, por ende, pueden concurrir todos los aseguradores que exploten el referido ramo. Esa libertad de concurrencia debe estar acompañada por una igualdad en el acceso a la información. En esa medida, todas las Aseguradoras Previsionales deben recibir la misma calidad de información en términos de suficiencia y pertinencia.

$\mathrm{Al}$ seleccionar el asegurador previsional, las AFP deben actuar de manera objetiva y, en esa medida, evitar la aplicación de criterios discriminatorios que no estén asociados a la capacidad patrimonial y técnica de la aseguradora respectiva.

Dichas licitaciones se deben realizar al menos cada cuatro años y el monto de la prima del seguro es pactado entre la Administradora de Fondos de Pen- 
siones y la Aseguradora previsional en función a la composición de afiliados al Fondo.

En el cálculo de la prima se aplican criterios actuariales en función a la siniestralidad que haya presentado la AFP en el pasado, así como el género y la edad de los afiliados. La prima del seguro previsional corresponde a un porcentaje de la comisión de intermediación mensual que reciben las AFP por el desarrollo de su objeto social.

La prima pagada al asegurador previsional cubre de manera integral a todos los afiliados al Fondo de Pensiones.

\subsection{LA RENTA VITALICIA Y EL RETIRO PROGRAMADO}

Una vez reconocida la pensión y pagada la suma adicional, el pensionado puede optar por contratar una póliza de renta vitalicia con una compañía de seguros o puede seleccionar un plan de retiro programado con la Administradora de Fondos de Pensiones.

En la renta vitalicia, el beneficiario traslada a la compañía de seguros el capital necesario para financiar la pensión correspondiente y, a cambio, recibe una renta mensual hasta su fallecimiento y el de su sobrevivencia, si aplicara.

En el retiro programado, la pensión la paga la AFP, pero los recursos permanecen en el patrimonio del beneficiario y el valor de la mesada se recalcula anualmente.

En esta última modalidad de pensión, los riesgos asociados al manejo de los recursos corren por cuenta del beneficiario de la pensión, mientras que, en el caso de las rentas vitalicias, quien asume los riesgos es la compañía de seguros.

Las aseguradoras previsionales tienen la obligación de cotizar las rentas vitalicias. En esa medida, las vicisitudes de las rentas vitalicias tienen incidencia directa en los seguros previsionales, toda vez que, a mayor nivel de capital necesario para financiar una renta, mayor será el monto de la suma adicional a cargo del asegurador previsional. No obstante, anoto que en el presente documento no se estudiarán a fondo las problemáticas asociadas a las rentas vitalicias.

\section{El riesgo judicial en el seguro previsional}

Los cambios demográficos y en la expectativa de vida de los colombianos han generado impactos importantes en el seguro previsional; sin embargo, la realidad es que, en adición a esos asuntos, que de suyo son relevantes, el riesgo judicial ha tenido un papel muy relevante en esta materia.

Ha sido así como, a través de múltiples pronunciamientos judiciales, tanto de la Corte Suprema de Justicia como de la Corte Constitucional se han intro- 
ducido cambios a la legislación que consagra los requisitos para acceder a una pensión de invalidez o de sobrevivientes y ello ha impactado de manera directa el seguro previsional. En particular, dichos pronunciamientos le han apuntado a flexibilizar o incluso eliminar ciertas exigencias para el reconocimiento de las pensiones de invalidez y/o de sobrevivientes.

A continuación, estudiaremos algunos de esos pronunciamientos y describiremos los impactos que han generado en el ramo previsional.

\subsection{FleXIbILIZACIÓn de REQUisitos PARA QUE LOS PADRES ACCEDAN A UNA PENSIÓN DE SOBREVIVIENTES}

El texto original de la Ley 797 de 2003 establecía que, en ausencia del cónyuge o de los hijos, la pensión de sobrevivientes la recibirían los padres, siempre y cuando estos dependieran total y absolutamente del afiliado o pensionado fallecido.

Este requisito de dependencia total y absoluta fue demandado ante la Corte Constitucional, por considerarse contrario a la Carta de i99i.

Es importante reconocer que dicha exigencia sirvió de base para que las aseguradoras previsionales objetaran reclamaciones asociadas a casos de padres que, si bien dependían económicamente de sus hijos, al percibir ingresos menores, veían frustrado su derecho pensional, toda vez que se aplicaba una interpretación bastante restrictiva según la cual, la aceptación "total y absoluta" exigía que hubiese una sujeción completa de los aportes del hijo fallecido para la manutención de los padres. Eso llevó a extremos tales como la emisión de objeciones cuando los padres reclamantes percibían ingresos menores derivados de algunas actividades informales que eran claramente insuficientes para garantizar su mínimo vital y móvil.

$\mathrm{Al}$ respecto, la Corte Constitucional, en la sentencia C-I I I de 2006, consideró que para que los padres acrediten su calidad de dependientes económicos no es necesario que carezcan en lo absoluto de ingresos propios o derivados de una fuente diversa a la de su hijo fallecido, pues bastará con que se pruebe que, sin el aporte del hijo, los padres no podrán subsistir de manera digna ni mantener el nivel de vida que llevaban antes del deceso.

Ha sido así como, a partir de dicha declaratoria de inexequibilidad, se ha venido aplicando un criterio según el cual se considera que los padres dependen económicamente del hijo fallecido, cuando los aportes de este último, además de garantizar su mínimo vital, son trascendentales para que los padres mantengan el nivel de vida que llevaban antes de la muerte del causante.

Esta postura de la Corte impactó de manera directa al seguro previsional en la medida que se cambiaron las condiciones para que los padres accedan al 
beneficio y, en esa medida, el número de reclamos procedentes se incrementó de manera sustancial.

\subsection{EL PRINCIPIO DE LA CONDICIÓN MÁS BENEFICIOSA}

Los orígenes de la condición más beneficiosa en el sistema de seguridad social colombiano se remontan a la expedición misma de la Ley ioo de I993, como una respuesta a las vicisitudes que generó un tránsito normativo de esa naturaleza.

Es así como el principio de favorabilidad, consagrado en el artículo 53 de la Constitución Política y aplicable al sistema de seguridad social colombiano, por remisión expresa del artículo 272 de la Ley roo de I993, se perfila como la piedra angular de la teoría de la condición más beneficiosa, que ha venido exponiendo en forma reiterada la jurisprudencia de la Sala de Casación Laboral de la Corte Suprema de Justicia.

El primer antecedentes de este asunto se remonta al año de I997, cuando la Corte Suprema de Justicia ${ }^{1}$ por primera vez expuso la teoría dicha teoría en un caso en el que se reconoció la pensión de sobrevivientes en favor de los derechohabientes de un afiliado al Instituto de Seguros Sociales, iss, quien falleció después de la expedición de la Ley roo de 1993 y que para esa fecha acumulaba un total de mil doscientas treinta (I.230) semanas, pero a quienes les negaron en un primer momento el derecho pensional, en la medida que para la fecha de su fallecimiento el causante no era un cotizante activo y en su último año de vida no cotizó el mínimo de veintiséis (26) semanas exigido. Siendo estos los requisitos exigidos por el texto original de la Ley roo de 1993, antes de la expedición de la Ley 797 de 2003.

En esa oportunidad, la Corte manifestó:

... ante la presencia de dos sistemas normativos de seguridad social de posible aplicación razonable, a juicio de la Corte, como son el Acuerdo 049 - decreto 0758 de r.990- y la ley roo de r.993, debe inclinarse el juzgador, con arreglo al texto 53 supralegal por la norma de seguridad social vigente al momento de culminación de la afiliación, esto es el primero de los estatutos mencionados, por ser el régimen más favorable a quien en vida cumplió en desarrollo de su labor con el sistema de seguridad social, para su protección y la de su familia.

En dicha providencia (que ha sido el sustento de los pronunciamientos más recientes) el alto tribunal indicó de forma clara refriéndose a la condición más beneficiosa: 
... sería violatorio de tal postulado y del principio constitucional de la proporcionalidad, entender que dentro del nuevo régimen de la ley ıoo-que redujo drásticamente el requisito de intensidad de semanas-, quedaron abolidas las prerrogativas de los derechohabientes originadas por afiliados que durante su vinculación como sujetos activos de la seguridad social habían cumplido todas las cotizaciones exigidas en el reglamento aplicable y antes de entrar a regir la nueva ley se desafiliaron del sistema al considerar fundadamente que por faltarles únicamente el requisito del fallecimiento sus familiares podrían reclamar la respectiva prestación al momento de su deceso... Si se acogiera tal solución fría y extremadamente exegética, se llegaría al absurdo que un mínimo de cotizaciones efectuadas durante solo seis (6) meses anteriores a la muerte dan más derecho que el esfuerzo de aportes durante toda una vida laboral, efectuado por quien cumplió con todos los cánones estatuidos en los reglamentos vigentes durante su condición de afiliado, lo cual no solamente atenta contra los principios más elementales de la seguridad social, sino también contra la lógica y la equidad.

Es así como la Corte cimentó su teoría de la condición más beneficiosa en el principio de equidad, en virtud del cual es desproporcionado que el ordenamiento jurídico desconozca las cotizaciones que un afiliado ha efectuado con anterioridad a la entrada en vigencia de una nueva normatividad, bajo la premisa de que la norma anterior establece unos requisitos mucho más exigentes que la vigente al momento de la estructuración o muerte.

En ese sentido, si la Ley roo de 1993 (en su texto original) hizo más laxos los requisitos para acceder al derecho pensional, con la finalidad de aumentar el nivel de personas beneficiadas con el sistema, la Corte consideró que resulta desproporcionado que a un afiliado que cotizó un mayor número de semanas en vigencia de normatividad anterior no se le reconozca la prestación económica.

En conclusión, la tesis de la Corte, aplicable para casos anteriores a la expedición de la Ley 797 de 2003, puede sintetizarse en que cuando en vigencia de la Ley roo de i 993 se produce la muerte o la invalidez de un afiliado que no está cotizando al sistema ni registra 26 semanas de cotización en el año inmediatamente anterior al fallecimiento, pero tiene aportes hechos con anterioridad a la entrada en vigencia de la citada Ley ıoo, la viabilidad de que sus causahabientes se beneficien de la pensión de sobrevivientes debe estudiarse a la luz de la legislación preexistente que establecía requisitos aún más exigentes, que en este caso viene a ser el Acuerdo 049 de I990, de suerte que si cumple los requisitos previstos en dicha normativa debe concederse el derecho respectivo.

Ahora bien, pese a la claridad con que la Corte esbozó en sus inicios la teoría de la condición más beneficiosa, los nuevos casos, la expedición de nuevas normas, las hipótesis que las mismas plantean y los fallos proferidos por la Corte 
Constitucional han llevado al alto tribunal a efectuar una serie de precisiones frente a la aplicación de la teoría.

\section{- ReQuisitos para aPLICAR las nORMAS del ACUerdo 049 de 1993}

Para la Corte, siempre ha sido claro que el Acuerdo o49 de I990 establecía dos vías para obtener el derecho pensional por esta vía: la primera, haber cotizado 300 semanas en cualquier tiempo y, la segunda, haber cotizado I 50 semanas en los seis años anteriores a la fecha de estructuración de la invalidez o de la muerte.

Es así como, sobre el primer supuesto, la Corte se ha pronunciado de manera reiterada indicando que la reseñada densidad de cotizaciones debe estar satisfecha para el momento en que empezó a regir la Ley Ioo de 1993, tema sobre el cual no existe la menor duda frente a su aplicación“; sin embargo, en el año $2006^{[2]}$, por primera vez la Corte abordó el estudio del caso de un afiliado que si bien no reunía las 300 semanas cotizadas en cualquier tiempo anterior al I de abril de I994, logró cotizar más de I 50 semanas en los seis últimos años en que estuvo vigente el Acuerdo 049 de 1990.

En ese caso, la Corte manifestó que para que el derecho a la pensión de sobrevivientes se gobierne por el Acuerdo 049 de 1990 en aplicación de la teoría de la condición más beneficiosa, resulta indispensable que se cumpla con los siguientes requisitos: en primer lugar, que al momento de entrar a regir la Ley roo de 1993 el afiliado haya cotizado I 50 semanas, y en segundo lugar, que el afiliado también registre $\mathrm{I} 50$ semanas dentro de los seis (6) años anteriores al fallecimiento.

Así mismo en dicha sentencia se aclaró:

(...) con el criterio expuesto no se está haciendo más gravosa la situación para los afiliados que reclamen la aplicación del régimen jurídico anterior con base en aportes por 150 semanas, sino cumpliendo con el imperativo legal que preceptúa que en este supuesto la densidad de semanas debe cumplirse dentro de los seis (6) años anteriores, pues del modo en que se dejó descrito resultan conciliados el mínimo de cotizaciones exigidos para el surgimiento del derecho y la fidelidad al sistema de seguridad social, que se manifiesta en que tal mínimo de aportes debe quedar hecho dentro de determinado interregno el cual debe ser relativamente cercano al momento de la muerte, siendo esta última circunstancia la que permite que se computen semanas cotizadas con posterioridad a la entrada en vigencia de la Ley roo de 1993. 
Adicionalmente, en sentencia posterior ${ }^{3}$, se adicionó una limitante a la aplicación de la condición más beneficiosa, consistente en que, para cumplir con las I 5 o semanas anteriores al siniestro, es necesario que el afiliado haya fallecido o que su invalidez se haya estructurado antes del primero (I) de abril de 2000, es decir, dentro de los seis años posteriores a la expedición de la Ley Ioo de I993, al señalar:

(...) y aunque -el causante- sí cotizó I 50 semanas en los seis años anteriores a la entrada en vigencia de la ley de seguridad social que abarca como se dijo hasta $\mathrm{el} \mathrm{I}^{\circ}$ de abril de $\mathrm{I} 988$, no satisface el otro requisito de reunir las ${ }_{5} 50$ semanas en los seis años que anteceden a la fecha de la muerte, bajo el entendido de que este periodo no puede extenderse más allá del sexto año de vigencia de la Ley ioo de 1993, precisión que se ha de hacer para quienes, como en el sub lite fallecen después del 3r de marzo de 2000.

\section{- Aplicación de la Condición más Beneficiosa en el RéGimen DE AHORRO IndIVIDUAL CON SOLIDARIDAD (RAIS)}

Inicialmente, los fallos proferidos por la Corte en aplicación de la condición más beneficiosa se referían a casos de afiliados al Régimen de Prima Media con Prestación definida, razón por la cual durante un buen tiempo se discutió la viabilidad de aplicar la teoría en el RAIs, toda vez que se entendía que el Acuerdo 049 de I990, por ser una norma expedida en su momento, para los afiliados al Iss, no debía aplicarse en favor de los afiliados a los fondos privados.

Dicha discusión fue zanjada a partir del año $200 \mathrm{I}^{[4]}$ cuando el alto tribunal manifestó que en atención a que los literales f y g del artículo I 3 de la Ley roo de I993, establecen dentro de las características del sistema pensional que las cotizaciones efectuadas en cualquier tiempo y en cualquiera de los dos regímenes se tendrán en cuenta para el reconocimiento de las prestaciones económicas que dicha norma consagra. Sobre el particular, refiriéndose a dichas normas, manifestó:

Por lo tanto, siendo claro que el parágrafo trascrito se refiere a los dos regímenes, es obvio también entender que las razones que expone la Corte para sostener que cumplidas las cotizaciones para el iss que con anterioridad a la ley roo de I993 confieren el derecho a obtener la pensión de sobrevivientes por la muerte de un afiliado al régimen solidario de prima media con prestación definida y con sujeción a lo previsto por los artículos $6^{\circ}$ y 25 del acuerdo 049 de 1990 , aprobado por el decreto $075^{8}$ del mismo año, son válidas y extensivas para otorgar igual derecho

3 Corte Suprema de Justicia, Sala de Casación Laboral, 4 de diciembre de 2006, expediente 28893.

4 Corte Suprema de Justicia, Sala de Casación Laboral, sentencia del cinco (5) de septiembre de 200 I, con ponencia del Magistrado Fernando Vásquez Botero. 
a un afiliado al régimen de Ahorro individual con solidaridad; máxime cuando se sabe que las cotizaciones que en este caso dan lugar al derecho a tal prestación social pasan al fondo respectivo representada en los llamados bonos pensionales, los que, al tenor del artículo i 5 de la ley roo de i993, "constituyen aportes destinados a contribuir a la conformación del capital necesario para financiar las pensiones de los afiliados al sistema general de pensiones”.

En consecuencia, a partir de dicha providencia, se extendió la aplicación del principio de condición más beneficiosa a favor de los afiliados a los fondos privados, situación que correlativamente ha impactado desde entonces al seguro previsional.

A partir de entonces, los jueces laborales vienen aplicando la norma más favorable a los intereses de los afiliados, aplicando el principio in dubio pro operario y dando efectos ultractivos a normas derogadas, cuando ello se ajuste a los casos en concreto.

\subsection{EL REQUISITO DE FIDELIDAD}

Como ya se anotó, el texto original de la Ley roo de r993 no contemplaba ningún requisito de fidelidad al sistema; sin embargo, dicha situación cambió a partir de la expedición de las leyes 797 y 860 de 2003.

De acuerdo con tal requisito, para acceder a una pensión de sobrevivientes o de invalidez, además de los requisitos ya estudiados, se debía acreditar cotizaciones al sistema por lo menos durante el $20 \%$ del tiempo transcurrido entre el momento en el que el afiliado cumplió 20 años de edad y la fecha del siniestro.

La expedición de esta nueva normatividad introdujo requisitos mayores a los establecidos en la Ley roo de I993 en su acepción original, situación que generó una reducción sustancial en el número de beneficiarios de pensiones de invalidez y sobrevivientes, lo que a su turno redundó en una disminución en las tarifas de las pólizas previsionales.

$\mathrm{El}$ inconformismo de los ciudadanos frente a la inclusión del requisito de fidelidad en la reforma no se hizo esperar y se tradujo en sendas demandas de inconstitucionalidad en contra de los artículos de la leyes 797 y 860 de 2003 que regulaban la materia. Fue así como mediante las sentencias $\mathrm{C}-428$ del $\mathrm{I}^{\circ}$ de julio de 2009 y C-556 del 20 de agosto de 2009, la Corte Constitucional declaró la inexequibilidad parcial del artículo i 2 de la Ley 797 de 2003 y el artículo I de la Ley 860 de 2003 , eliminando el requisito de fidelidad tanto en pensiones de sobrevivientes como de invalidez.

La Ley Estatutaria de la Administración de Justicia faculta de forma expresa tanto a la Corte Constitucional como al Consejo de Estado (órganos competentes para estudiar la exequibilidad de leyes y actos administrativos) para 
modular los efectos temporales de sus decisiones y, a su vez, establece que en el evento en que dichos efectos no sean modulados de forma expresa, se presume que tienen efecto general inmediato hacia el futuro.

Pues bien, tanto en la sentencia $\mathrm{C}-428$ del I $^{\circ}$ de julio de 2009 , como en la sentencia C-556 del 20 de agosto de 2009 , la Corte Constitucional se abstuvo de modular los efectos temporales de la declaratoria de inconstitucionalidad, razón por la cual algunos operadores jurídicos interpretaron que dicho requisito solo perdió vigencia en los casos ocurridos después de la expedición de dichas providencias ( $\mathrm{I}$ de julio y 20 de agosto de 2009 , respectivamente) y, en ese mismo orden, en los casos con fecha de siniestro anterior debía exigirse el cumplimiento tanto del requisito de densidad como el de fidelidad.

Después de haberse proferido las sentencias de inconstitucionalidad, la Corte Constitucional decidió modular los efectos temporales de su decisión y fue así como en sede de tutela indicó que la declaratoria de inexequibilidad tenía efectos retroactivos, debido a que las razones que provocaron la inconstitucional del requisito de fidelidad se remontan a la expedición misma de las leyes 797 y 860 de 2003, razón por la cual a juicio del Alto Tribunal debe entenderse que dicho requisito no puede exigirse en ningún caso. Nótese como, de forma poco ortodoxa (por decir lo menos), la Corte Constitucional trató de enmendar la omisión incurrida en las sentencias de exequibilidad, modulando sus efectos temporales en sede de tutela.

Debido a que los Fondos Administradores del Sistema de Pensiones empezaron a alegar en el marco de las acciones de tutela la inviabilidad de darle efectos temporales a una sentencia de exequibilidad en sede de tutela, la Corte Constitucional emitió la sentencia T-453 del 23 de agosto de 20 I I, con salvamento de voto de uno de los magistrados, mediante la cual proscribió de forma "general" la aplicación de tal requisito y le solicitó a la Superintendencia Financiera, y al Ministerio de la Protección Social, entre otras autoridades, “... instruir, vigilar e investigar, si es del caso al iss y a las Entidades Administradoras del Fondo de Pensiones, en procura de que no incumplan lo dispuesto frente a la inaplicabilidad de la "fidelidad al sistema".

Por lo anterior, el Ministerio del Trabajo y la Superintendencia Financiera de Colombia de forma conjunta expidieron la Carta Circular iog de 20 I I mediante la cual instruyeron a sus vigilados frente a la necesidad de adoptar mecanismos correctivos y de control necesarios que permitan la efectiva aplicación de los principios constitucionales, en los términos planteados por la Corte Constitucional, en cuanto a que "... el requisito de 'fidelidad al sistema' no puede ser exigido en ningún caso".

Es importante resaltar cómo, cuando se expidieron las leyes 797 y 860 de 2003, las aseguradoras previsionales disminuyeron sustancialmente las tarifas, 
debido a que observaron que el legislador estableció requisitos más exigentes; sin embargo, la declaratoria de inconstitucionalidad en el año 2009, es decir, más de 6 años después de haberse expedido dichas normas, generó una gran incertidumbre jurídica para los aseguradores. En mi opinión, lo adecuado hubiese sido darle aplicación futura y no retroactiva a dicha declaratoria de inexequibilidad, de manera que se respetaran las reglas de juego sobre el periodo ya transcurrido.

\subsection{FleXibilización de REQUisitos PARA LOS hIJOS}

El artículo I3 de la Ley 797 exigía que, para el reconocimiento de pensiones de sobrevivientes en favor de hijos mayores de edad, debía acreditarse la condición de encontrarse incapacitados para laborar en razón de sus estudios.

Para acreditar tal situación, la misma norma indicaba que dichos estudios debían cumplir con los requisitos mínimos establecidos por el Gobierno nacional, de lo que se desprendía que debía tratarse de estudios en instituciones educativas acreditadas y con una intensidad horaria mínima, lo que servía como filtro para otorgar el beneficio a aquellos hijos que realmente estuvieran en proceso educativo.

No obstante, los jueces en sus decisiones han venido aplicando unos criterios más laxos, reconociendo, en algunos casos, pensiones a hijos que no estudian en una institución educativa acreditada y sin un número mínimo de horas de clase a la semana.

\subsection{IMPRESCRIPTIBILIDAD DEL SEGURO PREVISIONAL}

Por tratarse de un seguro, inicialmente se entendió que el término de prescripción aplicable a las pólizas previsionales debía ser el regulado en el artículo io8 I del código de comercio, según el cual, los derechos derivados del contrato de seguro prescriben por la vía ordinaria o extraordinaria, entendiendo que en el caso de la ordinaria, el término será de dos años y empezará a computarse desde el conocimiento real o presunto del hecho que da base a la acción, mientras que la extraordinaria será de 5 años, correrá en contra todas las personas (incluso en contra de incapaces) y se computará desde que nace el derecho.

Prontamente, dicho entendimiento fue recogido y reformado por los jue$\operatorname{ces}^{5}$, quienes consideraron que, dado que el seguro previsional tiene como finalidad proveer la suma adicional necesaria para el reconocimiento y pago de pensiones de invalidez y sobrevivientes, y ante el carácter imprescriptible e irre- 
nunciable de tales prestaciones, era necesario hacer extensiva tal imprescriptibilidad a los seguros previsionales.

Esa postura ha tenido un impacto importante en el seguro previsional, dado que ha extendido aún más el tiempo de reclamación y ha generado que, en la práctica, demoras injustificadas de parte de las AFP en la formulación de los reclamos no tengan consecuencias jurídicas efectivas.

\subsection{Derechos pensionales para compañeros permanentes}

La norma que regula el reconocimiento de pensiones de sobrevivientes ${ }^{6}$ consagraba un tratamiento diferenciado cuando el reclamante ostentaba la condición de cónyuge, frente a aquel que lo hace en calidad de compañero permanente.

Era así como, en el texto original de la Ley 797 de 2003 no se exigía un tiempo mínimo de convivencia al cónyuge, mientras que el compañero permanente debía acreditar haber convivido con el causante al menos durante dos años.

Como es sabido, en el ámbito del derecho de familia, la calidad de compañero permanente se adquiere con el simple ánimo de compartir techo, lecho y mesa, sin que sea necesario acreditar un tiempo mínimo.

Fue así como, en una decisión tomada por la Corte Constitucional en el año $2007^{[7]}$, apelando al derecho a la igualdad, el Alto Tribunal declaró inexequible el requisito de convivencia mínima para el compañero permanente y estableció que, en ese caso, sería viable probar tal calidad mediante declaración notarial rendida por ambos compañeros.

En dicho fallo, la Corte fue más allá y estableció que la acepción compañero o compañera permanente, debe comprender tanto al del mismo como al del diferente sexo. De esa manera, la Corte abrió paso por primera vez en la historia jurídica colombiana al reconocimiento de derechos pensionales a parejas del mismo sexo.

Ambas decisiones, tanto la eliminación del tiempo mínimo de convivencia, como el reconocimiento de derechos pensionales a parejas del mismo sexo, ampliaron sustancialmente el espectro de potenciales beneficiarios de una pensión de sobrevivientes y tuvieron un impacto directo en el seguro previsional.

\section{Conclusiones}

Como se pudo apreciar, a lo largo de los años de existencia del seguro previsional se han producido importantes cambios derivados de decisiones jurisprudenciales. Ese dinamismo judicial ha generado cambios ostensibles en las condiciones

$6 \quad$ Ley 797 de 2003, artículo I3.

7 Corte Constitucional, Sentencia C-52 I de 2007. 
para acceder a una pensión de invalidez o de sobrevivientes en el régimen de ahorro individual y ha impactado de manera directa a los seguros previsionales.

Por supuesto, es razonable y necesario que la jurisprudencia en materias sociales como la que nos ocupa sea muy activa, lo que se alinea con los principios proteccionistas propios de estos asuntos; sin embargo, se echa de menos un mínimo de estabilidad jurídica para los actores del sistema, especialmente cuando, como ocurre en el caso de los aseguradores previsionales, cargan sobre sus hombros la responsabilidad de financiar las pensiones de invalidez y sobrevivientes, en aquellos casos en los que los saldos de las cuentas de ahorro individual no son suficientes.

En esa medida, estimo que los cambios en las reglas de juego deberían tener efectos futuros y no retroactivos, pues la reapertura de situaciones jurídicas consolidadas genera un especial desbalance para los agentes que intervienen en ellas.

En adición, en Colombia debería existir un mecanismo que limite de forma apropiada el poder del juez constitucional, de manera que no termine sobreponiéndose a las facultades legislativas que son del resorte del Congreso de la República.

Otro asunto de especial importancia en esta materia radica en la necesidad de limitar las facultades que hoy tiene la Corte Constitucional para dar órdenes generales en casos de tutela que por regla general tienen efectos entre las partes involucradas. Eso, también ha generado una profunda inseguridad jurídica, especialmente cuando se adoptan decisiones con efectos frente a terceros que no han podido intervenir en el debate judicial.

\section{Referencias}

Corte Constitucional, Sentencia C-i I I de 2006.

Corte Constitucional, sentencia C-52 I de 2007

Corte Constitucional, sentencia C-428 de 2009.

Corte Constitucional, sentencia C-556 de 2009.

Corte Constitucional, sentencia T-453 de 20 I I.

Corte Suprema de Justicia, Sala de Casación Laboral, sentencia de noviembre 2 I de 2007.

Corte Suprema de Justicia, Sala de Casación Laboral, sentencia de septiembre de 200 I.

Corte Suprema de Justicia, Sala de Casación Laboral, sentencia de diciembre 4 de 2006.

Corte Suprema de Justicia, Sala de Casación Laboral, sentencia de septiembre 26 de 2006.

Corte Suprema de Justicia, Sala de Casación Laboral, sentencia de agosto I 3 de 1997.

Carta Circular ıo9 de 20 I I, Superintendencia Financiera de Colombia. 